\title{
Story Theme in Literary Stylistics and Functional Stylistics
}

\author{
LI Han-bing \\ School of Foreign Studies, Beijing Information Science \& Technology University, Beijing, China
}

\begin{abstract}
Story Theme has been one of the major concepts in both literary criticism study and stylistic study. The essential characteristics of story theme might be summarized as being subjective and inter-subjective, social and generalized, pervasive throughout the whole text but covered, conventional and recoverable, and multi-faceted. This paper mainly discusses two stylistic approaches to story theme study. Literary stylistic approach focuses on the covert side and multi-levelness of story theme; while functional stylistics attaches much importance to the mechanisms that function to realize story theme.
\end{abstract}

Keywords: story theme, literary stylistic approach, functional stylistic approach

\section{Introduction}

Story theme can be regarded as the deepest meaning conveyed by a piece of verbal art. Wales (2001) defines "theme" in the study of literary criticism as the "point" of a literary work, its central idea, which we infer from our interpretation of the plot, imagery and symbolism. It is a topic that has often been discussed in the studies of literary criticism and stylistics.The studies in literary criticism usually take theme as a default term and focus on the evaluation and interpretation of literary works. Modern literary criticism is often influenced by literary theory, which is the philosophical discussion of literature's goals and methods. In contrast, stylistics studies interprets text in regards to their linguistic style. Literary stylistics especially focuses on the linguistic style of literary text.

In this paper, I use the term "story theme" to indicate that the current focus is on the studies of theme, especially the theme of fictions and novels. With the overviews of story theme in both literary criticism and stylistics, this paper aims to summarize the essential characteristics of story theme and to probe into two main stylistic approaches to theme study: the literary stylistic approach and the functional stylistic approach.

\section{What Are Story Themes?}

When we appreciate a piece of art, for instance, a painting, we wonder what's in it that makes it art, the lines, the shadowing, the color, or just any detail of it. Actually, it isn't any part of the painting, it is the entire painting, its lines, shadows, colors and everything else in it that make it a piece of art, and all these add up together impresses us with its aesthetic value.

The case of verbal art is much the same. Taking poems as example, every part of the poem has something unique to contribute to the reader's understanding of it, meter, rhyme, character, setting, imagery, tone, form and

LI Han-bing, Lecturer in theoretical linguistics and discourse analysis, School of Foreign Studies, Beijing Information Science \& Technology University, Beijing. 
symbol. Each plays an important part in establishing the total effect of the poem. There is a point in every poem where all the elements converge, the point is the aesthetic value of the whole piece of works. For fictional novels, the author conveys by the language of the text an aesthetic value or moral value, which is in turn understood by the readers via detecting its language patterns.

Literary stylistic studies tend to regard this value an additional layer of meanings embedded in the fictional text, in addition to that of the surface text. Oscar Wilde wrote in the preface to The Picture of Dorian Gray: All art is at once surface and symbol. The word "symbol” means that literary text usually carries an additional meaning besides the surface text can explicitly declares. Therefore, theme is neither clearly stated in the text nor safely identified by adhering to some textual principles, as the terms "underlying motives" (Cohen-Shalev, 2009, p. 95), “under current”, “underthought”, “depth”, “deeper level of meaning” (Abbot, 2012, pp. 562-563) or “context determined deeper-level meaning” (Shen, 2007, p. 53), “thematic import” (Shen, 2011, p. 586) can suggest. All these terms designate this additional meaning, which is understood as "meanings that lie compacted within what we observe on the surface” (Abbot, 2012, pp. 562-563).

Study of functional stylistics takes this underlying meaning of literary works as the symbolic articulation of specific aspect of human being's spiritual world, of human society, and of the interpersonal relationship among individuals, in the art form of literary fictions. As one of the greatest representative scholars in functional stylistics, Hasan (1985/2012, p. 7, 97) used the term "theme”. Among all the meanings of it, she used it in two different senses: theme in clause and theme in literature. Theme in clause refers to the element of the clause that represents the speaker's point of departure of information, and it is usually associated with clause-initial position, and it functions largely as a textual indicator, see Example (1) and (2):

Example (1) The gift my brother sent really amazed my kids.

Example (2) My kids were really amazed by the gift my brother sent.

"Theme" in Example (1) is "the gift my brother sent", which serves as the departure of the information, with the rest of the sentence indicating what is about the gift. That in Example (2) is "my kids", with the rest of the sentence focusing on what happened to "my kids". Another established functional linguistic scholar Martin used the term "thematic" to refer to the textual function of language, the function to organize information within clauses, and beyond that into larger units. In other words, thematic development governs the information flow as text unfolds in context of situation (Martin, 2010, p. 21).

"Theme" in literature, according to Hasan, is "what a text is about when dissociated from the particularities of that text”. She cited Frost's poem of "The road not taken” as an example. Taking the linguistic forms proper into consideration, this poem is about someone choosing to go down one road in the hope of coming back to the other, but never being able to do so. However, "theme” of this poem is much deeper and covert, which is about the limitations and immutability of human choices. Apparently, "theme” in literature is very close to "a generalization, a hypothesis about some aspect of the life of social man” (Hasan, 1985/2012, p. 97).

It can be safely concluded that functional stylistics attaches much importance to the social side of the meaning, while literary stylistics emphasizes the covert nature of it. These are quite insightful for they reveal the most essential characteristics of this underlying meaning of literary works. 


\section{Essential Characteristics of Story Themes}

On the basis of the above reviews of story themes, it is not hard to see that story theme is a special type of meaning and is essentially characterized by several features. It is subjective and inter-subjective, social and generalized, pervasive throughout the whole text but covered, conventional and recoverable, and multi-faceted. Some insightful ideas contribute to the above understandings are drawn from Halliday (1977/2002), Hasan (1971/2011), Poynton (1990), Miller \&Turci (2007).

\section{Subjective and Inter-subjective}

Story theme is subjective in the sense that it is the author's intention of creating the literary works. It is inter-subjective for it enables the readers to share and negotiate the meaning potential that the author intends to convey in the form of verbal art. As Halliday (1978, pp. 1-2) pointed out, language is a shared meaning potential, which is both a part of experience and an inter-subjective interpretation of the experience.

Poynton (1990, p. 40) argues that "subjective" could be understood as the essential nature of "subjectivity". Subjectivity is human individual's capacity for acting as social subjects. It is not given, but is created in and through the human individual's active participation in specific discourse that is operated in the societies in which they are members. In other words, by subjective we mean that reader's appreciation of the literary works inheres in the individual, therefore is subject to changes and variation. While by inter-subjective we mean that story theme could be the target or the object that different social individuals negotiate with one another. The other term that shares the similar meaning with inter-subjective is "interpersonal". Different readers could demonstrate their complying or confronting stances. They may offer their sympathy or indifference to the fictional characters depicted by the author. The term "inter-subjective" is often used to denote the author's way of manipulating the languages in order to ally with the putative readers, therefore is operated in the communication level between the author and the putative readers.

\section{Social and Generalized}

In the study of functional linguistics, Hasan had always advocated viewing story theme of verbal art from the social historical background in which the works was produced. On one occasion she analyzed an English poem and said:

To explore these universal themes of human existence bracketed between being and not being, to articulate artistically the sense of such a vast universe of feeling, longing, action and emotion as a coherent metaphor, verbal art relies most on two indispensable matrices as its sources of energy--the powerful semiotic system of language and the intricately woven fabric of the semiotically shaped culture. (Hasan, 2011, p. xvii)

In Hasan's statement she vigorously stressed the social cultural settings in which the literary works is created. Miller \&Turci (2007, p. 6) echoed a similar view that literary texts always articulate a generalization on the nature of social existence.The assumption that literary works will always target at airing the author's views of specific aspect of social life will win the agreement of most of us. For example, the story theme of love, death, war, immigration, friendship and marriage always presuppose the participation of human individuals. Even that of nature and of wild life will inevitably touch the issue of man-nature or man-wildlife relations. The feature of "social" is what inherently embodied in the creation of literary works, and that of "generalized" is largely what makes these works highly appreciable by individual readers and everlasting through different ages and across different spaces. These features make story theme of verbal art a fascinating topic to pursue. 


\section{Pervasive in the Whole Text but Covert}

Being subjective and inter-subjective, social and generalized indicate that story theme is quite different from what the surface text can literally carry. This can be understood in more than one sense.

In one sense, story theme shouldn't be simply equated to a single sentence of the fictional text; instead it is based on the author's manipulation of the word choice throughout the text. We can also say that story theme is expressed dynamically and is dispersed across the individual sentences, paragraphs and even larger text spans. In this sense story theme does not resides in here or there of the text, but in everywhere of it. The feature of being pervasive in the text indicates that the focus on merely some local part of the text is not feasible.

In the other sense, story theme, as the author's intentional purpose of creation, will not present itself automatically or literally in the text. In other words, it is implied or covert. Since story theme is not accessible merely via reader's intuition or experience, only a close study of the patterns of the language will reveal this underlying meaning.

\section{Conventional and Recoverable/Inferable}

Conventionality is one important aspect of story theme and being conventional means being accessible. The underlying story theme could be uncovered by exploring the language patterns embodied in the text. Halliday (1971/2002, p. 107) considered syntactic pattern as a type of "syntactic imagery". He argued that "The syntactic vision/imagery of things is seen as coincides with, and is an extension of, the reality" (p. 107).

In Halliday's view, the notion of "reality" is assumed to be the real world as contrasting to the fictional world. Syntactic imagery imitates the real world experience, which enables the syntactic patterns to be perceived and understood by the putative readers. Besides, fictional reality is seen as both superseding and imitating the real world experience, that is why story theme is ultimately recoverable in spite of being covert. Readers might always find some trace that indicate the parallel between fictional world and real world.

The essential characteristics of story theme shed light on the approaches to study story theme. The following part aims to probe literary stylistic approach and functional stylistic approach since both the two attach much importance to the mechanism of how wording construes meaning.

\section{Literary Stylistic Approach to Story Theme}

Literary stylistics (represented by Leech \& Short, 1981, pp. 182-183) approaches to story theme from the perspective of author-reader communication. They argue that story themes are the meanings that are evoked by the readers of the literary text. The author's depiction of specific events and characters might evoke the reader's emphatic or unsympathetic response. For example, in an excerpt of Hemingway's The Short Happy Life of Francis Macomber, the author gives a detailed physical depiction of a wounded lion.

Thirty-five yards into the grass the big lion lay flattened out along the ground. His ears were back and his only movement was a slight twitching up and down of his long, black tufted tail. He had turned at bay as soon as he had reached this cover and he was sick with the wound through his full belly, and weakening with the wound through his lungs that brought a thin foamy red to his mouth each time he breathed. His flanks were wet and hot and flies were on the little openings the solid bullets had made in his tawny hide, and his big yellow eyes, narrowed with hate, looked straight ahead, only blinking when the pain dame as he breathed and his claws dug in the soft baked earth. (Leech \& Short, 1981, p. 183) 
Despite the seemingly objective description of the wounded lion, especially the adjectives that are used (big, long, black-tufted, thin, foamy, wet, hot, solid, tawny, big, yellow, soft, baked), reader's imagination is still able to work on these details. These evoke a pitying sense of the animal's suffering in the reader's mind. This is partly attributed to Hemingway's "theory of omission" (Leech \& Short, 1981, p. 183). Leech and Short use the term "significance", as most stylisiticans do, to refer to "story theme" that is adopted in the present paper. They argue that "significance" of a literary text "comes through what is unstated, but implied, as much as through the meanings of the words on the page" (p. 183).

It can be inferred that literary stylistic approach represented by Leech \& Short (1981) stress much on the implicit and covert side of thematic meaning. They based their argument on the supposition that literary text consists of different communicative levels. The communicative level between different fictional characters can be seen as the basic level, which is embedded in another level between the narrator and the putative readers.

The theory of different communication levels is enlightening, since one could safely conclude that story theme could be recovered from the text via reader's response. This recognition or inference of story theme in fictional text is achieved by the stylistic feature of "foregrounding".

"Foregrounding” was put forward by Prague School scholar Mukarovsky (1964) and was later translated into English. He took foregrounding as a type of deviation from the established standard or usual form of language. In literary works foregrouding is often attached to literary relevance, and can be taken as contrast between two or more different language features. One example is Leech and Short's analysis of one excerpt of The Secret Agent. In the story plot, the protagonist Mr. Verloc was murdered by his wife with a knife. The author, when describing this plot, didn't adopt the usual way of portraying Mrs. Verloc as holding the knife and thrusting it into her husband's heart. Instead, he used the clauses that take the knife as subject:

He saw partly on the ceiling and partly on the wall the moving shadow of an arm with a clenched hand holding a carving knife. It flickered up and down. Its movements were leisurely. They were leisurely enough for Mr Verloc to recognize the limb and the weapon.

.... But they were not leisurely enough to allow Mr Verloc the time to move either hand or foot. The knife was already planted in his breast. (Leech \& Short, 1981, p. 237)

Leech and Short point out that the author's overtone of diverting Mrs. Verloc from her actions of murder is realized by the unusual ways of taking the weapon instead of the murderer as the subject of the sentence.Taking the knife, compared with taking Mrs. Verloc, as the subject is a type of foregrounding. Hasan (1985/2012, pp. 14-5) considered "foregrounding" as the repetition and contrast of language patterns in literary works. She pointed out that language itself is a patterned activity. Pattern can be the repetition of individual words, or language units larger than words, for example, parallel structures. The significance of pattern in stylistic analysis lies in their literary function. The function of foregrounding in this case is to divert the murderer from her action of murder.

Patterns have two types, form patterns and meaning patterns. Form patterns could be individual word, group of words, or sentence structure. Corpus linguistic study has a tradition of probing the occurrence of individual word or lexeme in specific text span. The usual practice is to use some corpus retrieval tool to conduct a thorough survey of the target word or lexeme in certain electronic readable text. The purpose is to learn about the frequency 
and distribution of the target language unit, and to identify the local co-text of it. Such local co-text in addition to the target language unit is a type of word pattern.

Two examples are cited as follows to illustrate the study of word pattern. Turci (2007, pp. 97-98) investigated the frequencies, collocation patterns and dispersion of the lexeme "dark" in Joseph Conrad's Heart of Darkness. Turci found that the collocation of dark function to reveal the dark and inhumane side of the African colonists. Stubbs (2008, pp. 451-452) made a research of the occurrence and frequency of the co-text of "grass" in Joseph Conrad's Heart of Darkness. Stubbs used the term "semantic prosody" to refer to the meanings that are created by the collocation of "grass" and the words that highly occurred with "grass". By investigating this collocation he found that the word "grass" usually associates with death, decay and desolation.

Meaning patterns are similar to form patterns in that both may contribute to foregrounding when collaborated with story theme in fictional text. The difference between these two lies in that form pattern usually equal to the words or phrases of the surface text. Meaning patterns, however, are actually the configuration of some specific grammatical or semantic labels. Leech (1966/2011, pp. 4, 13) used the term "parallelism" (used in the study of rhetoric, and one form of syntagmatic regularity of language) to refer to the repetition of the similar or same configuration of grammatical labels, for example, in the sentence "He found his key and opened the door", the repetition of the grammatical configuration "verb+object" could be taken as a weak form of parallelism.

Configuration of grammatical labels, according to previous researches, might also concern the contrast of different mood types, or voice types. Stubbs (2008, p. 454) explored the function of negative grammatical markers (shortened as "negatives" here after). By investigating a few electronic readable texts he summarized the functions of negatives in the genre of fictional novels: signaling subjectivity, highlighting the unexpected aspects of the scene, implying more than literally said, and serving an alienation device by representing the fictional world as being strange, foreign and alien.

Domestically, Liao (1999, p. 15) explored the function of negative mentality depiction in narration. In the article of "Hiroshima — the Liveliest City in Japan". She found that the structure "I didn't understand...”, "they didn’t appear to....”, “I didn’t expect...”, etc. function to reveal the conflicting inner state of the narrator. The reporter was eager to know the Hiroshima residences' true psychological state after they had experienced the atomic attack during the Second World War. However, he was afraid to touch the most inner part of these people since the atomic bomb must had hurt them to the extent that they were unwilling to mention it. Liao (1999) argued that the use of negatives vividly reflect the narrator's conflicting inner world.

Ren (2003, pp. 8-9) in his analysis of Soldier's Home detected three foregrounded syntactic patterns: declarative, counter-expectancy and negation. The declaratives taking the protagonist Krebs as subject can be found in the structure of "he liked to...he liked....". The negatives are repeated in the sentences of "Krebs didn’t feel....”, "not wanted to ... ”, "not worth it...”, and “didn’t want to....”.

The contrast formed by the declaratives and negatives reveal the protagonist's passive psychological state and indifferent attitude towards life. Although he was still young after returning from battlefield to hometown, he had yet lost the hope and enthusiasm that was typically possessed by men of his age. Although he could still get near to the ladies who were once attractive to him, he just didn't have the impulse to pursue love romance any longer. These all indicate that the war had destroyed the man spiritually despite his physical health. That is to say, 
the negatives cited in the previous paragraph form a syntactic or grammatical pattern, which symbolically implied the protagonist Krebs' negative and pessimistic attitude towards the post-war life. The use of negative structure and that of non-negative structure thus form a contrast, which the Prague School stylistics treated as "foregrounding"- - a type of contrast between different patterned structures as well as the meanings indicated by the structures.

In addition to the above mentioned analysis, Ren (2000, p. 111) also surveyed the language of the novel The Luncheon authored by Maugham, He summarized the most frequently occurred structures in the female reader's speeches. She repeatedly declared that she wouldn't eat anything for luncheon:

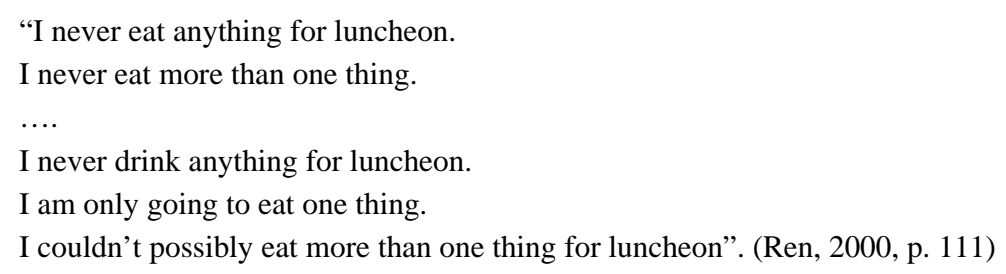

However, her manners over the dinner indicated that what she said wasn't true at all. As Maugham described:

She ate the caviar and she ate the salmon. I watched the abandoned woman thrust them [asparagus] down her throat in large voluptuous mouthfuls. (Ren, 2000, p. 111)

Ren commented that in the fictional text the pattern of "I never eat...." and "I only eat....” in the female's speeches form a sharp contrast with her behaviors. By this contrast Maugham conveyed a strong sense of irony towards the female reader.

Negatives, declaratives and other grammatical or syntactic structures form configurations in which semantic labels are realized or coded by wordings. The configurations are more abstract than grammatical labels in the sense that the former is the representation of the latter. This concerns the function of the wordings in literary text, which is the focus of functional stylistic approach to story theme.

\section{Functional Stylistic Approach to Story Theme}

Functional stylistics, according to Liu and Song (2015, p. 278), could be understood in broad sense as covering the Prague School functional approach to linguistic study, Halliday's systemic functional linguistics and Bakhtin's theories of speech genre and style.

In its narrow sense, functional stylistics refers exclusively to the studies taking systemic functional grammar as the theoretical framework. In this sense, functional stylistics can be called "systemic functional stylistics". The present paper uses the term "functional stylistics" in its narrow sense. Functional stylistics has two major theoretical foundations: the social semiotic view of language (Halliday, 1978) and systemic function grammar (Halliday, 1985).

\section{The Social Semiotic View of Language}

The Social Semiotics of Language (Halliday, 1978) is universally acknowledged as the fundamental works that proposed and elaborated on the assumption of "language as social semiotic", which takes language as a strata and systemic network and the use of language as a meaningful choice from the network. In addition, it attaches 
much importance to the situation and culture in which the language is used, and thus is a social-oriented approach to language study.

The social semiotic view of language is the guiding principle of all the studies in the academic trend of systemic functional linguistics. The genre of literary works could be regarded as a special variation of language in general.

The social semiotic view is significant for stylistic study in two ways. The first is to remind the researcher that meanings in literary works are always meanings related to specific situational and cultural context, thus the interpretation and evaluation of literary works should be inseparable from the story plot and social background in which the literary works creates. The second is to point out that meanings of literary works are multi-layered, with the story theme the deepest layer of meaning being realized by various grammatical and syntactic patterns. As Halliday (1978, p. 137) argued that language in general is meaning potential, and texts are instance of this meaning potential. Literary text actually project the meanings at a higher level of semiotic. This higher level semiotic system is faceted and layered in much the same way as the linguistic system itself.

\section{Systemic Functional Grammar}

Functional stylistics is characterized by its focus on various semantic patterns that function to bring out the underlying story theme. One type of the semantic patterns are different figure types of the transitivity system, which refers to the networks realizing the experiential meaning. Systemic functional grammar (Halliday 1985) construes the experiential world into various types of processes. For example, Material processes realize the experience of happenings and doings, Mental processes realize our inner thoughts and feelings, Verbal processes project what we speak. Various sets of semantic labels function to bridge the linguistic expressions and the experiential world depicted by the fictional text. Each process is represented by a series of grammatical labels, for example, Material process can be represented as: Actor $\wedge$ Process: effective type $\wedge$ Goal.

The labels of "Actor" and "Goal" respectively indicate the person who exert influence on others and the person who is influenced as a result. The label of "Process" represents the action implemented by the Actor. Besides this pattern, Material figure may also be represented as: Actor ${ }^{\wedge}$ Process: middle type. This figure differs from the effective type in that the action denoted by the verb doesn't exert any influence on others.

As far as story theme of literary works is concerned, researches in the field of functional stylistics usually relate specific figure patterns to the underlying story theme of the literary works.Taking Halliday' analysis of The Inheritors (1971) as an example, he studied the figure patterns that the author respectively used to depict both the aboriginals and the inheritors. Analyses show that the aboriginals are usually described as Actor (in the figure of “Actor $\wedge$ effective type of Material Process $\wedge$ inanimated non-human Goal” or in that of "Actor $\wedge$ middle type of Material Process”) whose actions don’t exert any influence on anybody else except themselves.

However, the inheritors are frequently described as Actor (in the figure of "Actor $\wedge$ effective type of Material Process ^ human Goal”) whose actions have effect on the aboriginals. The contrast of the figure patterns that are used to depict the experiences of the two groups of people function to reveal the story theme that the aboriginals were under-developed intellectually and they would inevitably be replaced by the new comers.

In brief, the social semiotic view of language brings language form, language meaning and the situational context in which the language is used into a holistic framework, which are highly suggestive for literary works 
with full-developed fictional plots. The contribution of systemic functional grammar to functional stylistics resides largely in the system of semantic patterns available in the analysis of literary text, and the transitivity system is one case in point.

According to Liu \& Song (2015, p. 282), Halliday's works (1971) can be taken as the first stage of development of functional stylistics. The second stage was represented by Hasan (1985/2012), who put forward and elaborated on “the semiotic of verbal art”. Hasan's works partly reiterates Halliday's (1978) social semiotic view of language and partly goes one step further.

\section{Hasan's Semiotic System of Verbal Art}

As one of the prominent contributors to the study of functional stylistics, Hasan (1971/2011, 1985/2012, 2007) made a series of studies of the language patterns in the genre of poems and short stories. Her analyses cover transitivity patterns, mood and modality patterns and thematic patterns. In her studies of literary works she always bear in mind the specialty of literary text as contrasted with non-literary text, and her concern of this issue can be detected in her argument of the necessity of a well-grounded argument of the underlying story theme in literary works.

What is the nature of engaging with literature? ....this intends to throw new light on many taken-for-granted attitudes regarding literature by bringing them face to face with arguments from the social semiotic approach to language. (Hasan, 2007, pp. 15-16)

Hasan endeavored to make the study of literary works, especially the researcher's interpretation of the works based more on facts than on assumptions. Her emphasis of the key role language patterns play in the process of literary interpretation can be seen from "the semiotic of verbal art".

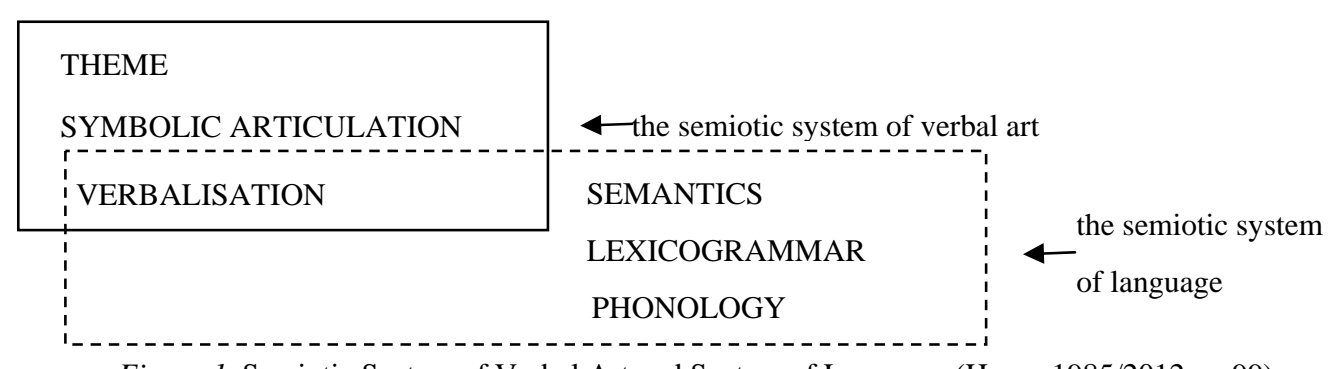

Figure 1. Semiotic System of Verbal Art and System of Language (Hasan 1985/2012, p. 99)

In the semiotic of verbal art, meaning of literary works is considered "a semiotic system with strata of THEME, Symbolic articulation, Verbalization” (1985/2012, p. 96). The stratum of THEME can be understood as "story theme" that the present paper aims to elaborate on.

Verbalization are virtually language patterns, the re-occurring grammatical or semantic structures in different location of the text. Patterns create a specific effect in an accumulated way. This effect can be aesthetical or moral or both. Readers by appreciating these patterns could uncover the author's intended communicative purpose of creating the works.

SYMBOLIC ARTICULATION could be understood essentially as a process of instantiation that brings out the underlying story theme of literary works via specific language patterns. It provides a mechanism that enables language patterns to acquire literary significance. As Halliday (1971/2002, p. 106) points out that by 
manipulating the language patterns Golding is offering a "particular way of looking at experience". These patterns create "syntactic imagery", which in turn symbolically indicate the underlying story theme of "survival of the fittest”.

In summary, the semiotic of verbal art highlights the function of language pattern in symbolizing story theme; therefore makes the literary interpretations more reliable and persuasive. Besides, it provides the general guiding principle of social semiotics with concrete and practical model of analysis.

\section{Conclusion}

Story theme, as the deepest meaning embedded in verbal art, has received much attention in the studies of both literary criticism and stylistics. Literary stylistics and functional stylistics approach story theme from slightly different perspectives. The former focuses on the double communication levels as well as the covert nature of story theme; while the latter mainly focuses on the mechanism in which story theme is construed and the grammatical patterns by which story theme is represented. No matter which approach is adopted, the essential characteristics of story theme should always be born in mind, which might be open to further exploration.

\section{References}

Abbot, H. P. (2013). Style and rhetoric of short narrative fiction: Covert progression behind Overt Plots (Book Review). Style 2013, 47(4), 560-565.

Cohen-Shalev, A. (2009). Beyond reconciliation filial relationship as a lifelong development theme in Bergman’s films. Style V., 43(1), 86-108.

Halliday, M. A. K. (1971). Linguistic function and literary style: An inquiry into the language of William Goldings's The Inheritors. Reprinted in J. Webster (Ed.), Linguistics studies of text and discourse. The collected works of M. A. K. Halliday (Vol. 2) (pp. 88-125). London: Continuum.

Halliday, M. A. K. (1978). Language as social semiotic: The social interpretation of language and meaning. London: Edward Arnold.

Halliday, M. A. K. (1985). An introduction to functional grammar. London: Edward Arnold.

Hasan, R. (1971/2011). Rime and reason in literature. Selected works of RUQAIYA HASAN on Applied Linguistics (pp. 363-397). Beijing: Foreign Language Teaching and Research Press.

Hasan, R. (1981/2011). What's going on: A dynamic view of context. Selected works of RUQAIYA HASAN on applied linguistics (pp. 243-260). Beijing: Foreign Language Teaching and Research Press.

Hasan, R. (1985/2012). Linguistics, language and verbal art. Beijing: The World Publishing Company.

Hasan, R. (2007). Private pleasure, public discourse: Reflections on engaging with literature. In D. R. Miller \& M. Turci (Eds.), Language and verbal art revisited: Linguistic approaches to the study of literature (pp. 13-40). London: Equinox.

Hasan, R. (2011). Rime and reason in literature. Selected works of RUQAIYA HASAN on applied linguistics (pp. 363-397). Beijing:Foreign Language Teaching and Research Press.

Leech, G. (1966/2011). Linguistics and the figures of rhetoric. Selected works of Geoffrey leech on applied linguistics (pp. 3-22). Beijing: Foreign Language Teaching and Research Press.

Leech, G., \& Short, M. (1981). Style in fiction: A linguistic introduction to English fictional prose. London: Longman.

Liao, Q. Y. (1999). The application of systemic functional grammar in stylistic analysis. Foreign Languages and Their Teaching, (8), 14-17.

Liu, S. S., \& Song, C. F. (2015). New developments in functional stylistics. Modern Foreign Languages, 38(2), 278-286.

Martin, J. R. (2010). Tenderness: Realisation and instantiation in a Botswanan town. In Z. H. Wang (Ed.), SFL Theory Vol. 1: Collective works of J R Martin (pp. 7-23). Shanghai: Shanghai Jiao Tong University Press.

Miller, D. R., \& Turci, M. (Eds.). (2007). Language and verbal art revisited: Linguistic approaches to the study of literature. London: Equinox.

Mukarovsky, J. (1964). Standard language and poetic language. In Paul L. Garvin (Ed. and Trans.), A prague school reader on 
esthetics, literary structure, and style (pp. 17-30). Washington, D.C.: Georgetown University Press.

Poynton, C. M. (1990). Address and the semiotics of social relations: A systemic-functional account of address forms and practices in Australian English (Ph.D. Thesis, Sydney: University of Sydney).

Ren S. Z. (2000). The Meaning of language pattern: An approach to study story theme. Foreign Language Teaching and Research, (2), 110-116.

Ren, S. Z. (2003). Multi-level semantic structure in narrative. Foreign Language Research, (1), 1-12.

Shen, D. (2007). Internal contrast and double decoding: Transitivity in Hughes’s “On the Road”. Journal of Literary Semantics, (36), 53-70.

Shen, D. (2011). Neo-Aristotelian rhetorical narrative study: Need for integrating style, context and intertext. Style, 45(4), 576-597.

Stubbs, M. (2008). Conrad in the computer: Examples of quantitative stylistics methods. In Shen (Ed.), Recent development in western stylistics (pp. 440-465). Shanghai: Shanghai Foreign Language Education Press.

Turci, M. (2007). The meaning of 'dark’ in Joseph Conrad's Heart of Darkness. In D. R. Miller and M. Turci (Eds.), Language and verbal art revisited: Linguistic approaches to the study of literature (pp. 97-114). London: Equinox.

Wales, K. (2001). A dictionary of stylistics (2nd ed). Harlow, England: Longman. 